\title{
Ontology-Driven E-Learning System Based on Roles and Activities for Thai Learning Environment
}

\author{
Chakkrit Snae and Michael Brueckner \\ Faculty of Science - Naresuan University, Phitsanulok, Thailand
}

\author{
chakkrits@nu.ac.th michaelb@nu.ac.th
}

\begin{abstract}
In this paper the authors present an e-learning management system with metadata that serves as a general template for the situation of Thai learners. Basically it is an ontology-driven e-leaning system for Thai learning environment (O-DEST). The system comprises an ontology for the elearning process, such as course syllabus, teaching methods, learning activities, and learning styles. O-DEST helps teachers, students and administrative personnel to set up and maintain the course material as well as the course administration, to go through the learning content, and to administer student and teacher data. Ontologies for the knowledge domain specific teaching subjects will enable the usage of the teaching contents in the Semantic Web.
\end{abstract}

Keywords: E-learning system, ontology, Semantic Web, Thailand

\section{Introduction}

E-learning courses have to serve very different learner groups and can be presented in many different forms. There are novice learners, intermediate and advanced up to experienced students.

Furthermore, e-learning courses can be attended by dependent or independent learners who study full-time or part-time. On the other hand e-learning is based on certain prerequisites, such as management, culture, and IT (Maurer \& Sapper, 2001).

E-learning has proven to be useful in tertiary education, e.g. universities, and in companies where lifelong learning is a must. Contents of e-learning range from technical knowledge to soft skills, like social behavior. Nevertheless, classroom training can never be completely removed by elearning (Bachman, 1999). There are several forms of teaching e-learning courses, such as Computer-Based Training (CBT), where the learners execute customized software on a standalone or networked computer, or Blended Learning Classes, where e-learning works hand in hand with other educational resources. A learning form which becomes more and more popular among Thai students is the provision of digital learning games.

Material published as part of this journal, either on-line or in print, is copyrighted by the Informing Science Institute. Permission to make digital or paper copy of part or all of these works for personal or classroom use is granted without fee provided that the copies are not made or distributed for profit or commercial advantage AND that copies 1) bear this notice in full and 2) give the full citation on the first page. It is permissible to abstract these works so long as credit is given. To copy in all other cases or to republish or to post on a server or to redistribute to lists requires specific permission and payment of a fee. Contact Publisher@InformingScience.org to request redistribution permission.
All of these forms can be enhanced by suitable and appropriate multimedia content, such as e-books, streaming videos or audio files, where details and information are kept in multimedia files or sound and can be accessed via the Internet, and e-libraries, where we can borrow books online and check the availability of books. 
The e-learning communities are quickly embracing many modern web technologies. Examples include the introduction and increasing use of meta-data, content structure, and digital repositories, but many e-learning applications are highly monolithic and seriously lacking in flexibility (Naeve, Nilsson \& Palmér, 2001).

Specifying reusable elements of learning content and defining an abstract way of describing the design for different components of teaching material are two of the most current research issues in the e-learning community and can be described by Learning Object Metadata (Knight, Gašević, \& Richards, 2006). A learning object is defined as any entity, digital or non-digital, that can be used, re-used, or referenced during technology-supported learning (Duval, 2002). However, learning objects require ability to semantically express relations among different types of objects in the context of e-learning (Koper, 2001).

The e-learning management systems are integrated systems that support a number of teachers' and students' needs and are much more successful in web-enhanced learning education. Learning management systems enable teachers to compose their courses from newly created and existing elearning material. These components of the system are modeled and described by standard structure and metadata and can be used in many courses and for different purposes.

We use an e-learning management system to mainly focus on constructing context, metadata and reusability of learning objects, and executing collaborative and administration tasks. An appropriate authoring tool in the e-learning management system can be used to adapt the learning content structure individually to improve the students' skills and knowledge. The system is an ontologydriven e-leaning system for Thai learning environment (O-DEST).

O-DEST provides a unified platform for logging, assessing, planning, delivering contents, managing records, and reporting. These activities help both the self-paced and the instructor-led learning processes. All these activities are represented to the end user (or organization) as web based applications. In fact, learning management systems are highly distributed systems in the web. One course presents an integrated structure of many learning resources that can be hosted on different web locations. The same resources can be combined with others to set up different courses. Also, more student groups can learn many courses at the same time. In these conditions, the system must have powerful management features. This means that a system needs specialized e-learning system properties and the capacity to perform the described components and metadata of the elearning system.

This paper is organized as follows. In the first chapter the paper describes the background of elearning systems, their forms of presentation and multimedia content generally accepted as valuable presentation forms. The next chapter is about the motivation for e-learning, especially in Naresuan University. Then the authors outline the general content of the e-learning system, the system architecture and design as well as the components of the system. Next the paper presents how the users, like students and administrators, can influence the system behavior. Finally the authors show their conclusions and present an outline of further work which has to be done.

\section{Why E-learning?}

E-learning increases productivity in education in that it provides access to learning materials at any time and at any place. The Internet and the World Wide Web are part of everyday life of students and teachers at any level all over the world. E-learning can meet the needs of a knowledgebased society which is one of the aims of Thailand for the year 2010. The knowledge-based society needs lifelong learners who are more or less independent in their studying habits (Brueckner \& Tetiwat, 2004). E-learning leads from mere information transmission to knowledge construction (Bates, 2005). 
E-learning can meet diverse user needs and requirements. E-learning can be consumed just in time at home or at the working place. It can be designed for the user's context in small parts of learning content. The content can be made available to a large number of participants. Participants can work out the material self-paced and so maximum information retention is more likely. As learners study in their natural environments travel costs and associated expenses are considerably reduced.

E-learning refers to computer-enhanced education but is extending to emerging technologies such as mobile computing (m-learning) and Personal Digital Assistants (PDAs). E-learning may include the use of web-based technologies, including blogs, polls (electronic voting systems), simulations, games, and Wikis. The differentiation to blended learning is floating. E-learning systems naturally suit distance learning, but are mostly also used in conjunction with face-to-face learning.

Naresuan University is an institution which serves as a hub of tertiary education for the lower Northern part of Thailand. The area covered is very large so the idea of independent learning via the Internet is quite intriguing. While there are first experiences with e-learning systems like ATutor (http://www.atutor.ca/) the overall usage is not given. E-learning systems have to take into account certain aspects of the audience they address, e.g. the knowledge and skills already obtained by the students, the background of the students and language levels. Moreover there are cultural aspects which may be related to the learning outcome, but evaluation of that is still in its infancy.

The experiences with Thai students show a significant lack of self-control and independence of learning and of creative and critical thinking with regard to average Thai students at Naresuan University as well as abroad (Viartas \& Sangkamnee, 2000). Also, reading is not a common habit of Thai students. Rote learning and learning by example are common ways of learning in Thai culture as well. E-learning on the other hand requires a high level of discipline from the learner which is often simply not the case for Thai students as Thai students have less of a sense of participation as an attitude towards learning. Face-to-face interaction between academics is the preferred method of learning and teaching rather than virtual interaction (Tetiwat \& Huff, 2003). The e-learning system for Thai students has to take these differences into account and offer appropriate help to the user.

Therefore, the learning material for Thai students should treat a specific topic in different ways, such as multimedia content, video training, and learning games. Through this Thai students are likely to be attracted by the learning material and can get a clear guidance for their studies, especially in distance learning courses.

\section{Why Ontologies?}

The term ontology has been widely used in recent years in the field of Artificial Intelligence, computer and information science especially in domains such as, cooperative information systems, intelligent information integration, information retrieval and extraction, knowledge representation, and database management systems (Guarino, 1998). Many different definitions of the term are proposed. One of the most widely quoted and well-known definition of ontology is Gruber's (Gruber, 1993): An ontology is an explicit specification of a conceptualization.

The term is borrowed from philosophy, where an ontology is a systematic account of existence. Here in this paper we adopt the following definition: Ontology is the study or concern about what kinds of things exist - what entities or things are there in the universe. Our work on ontologies will comprise: an terminological component where we lay down the concepts and an assert ional component (or knowledge base) which contains the individual instances (entities). The level of 
description will be taxonomies with hierarchically related terms and controlled vocabularies (thesaurus) with the help of semantic networks (Snae \& Brueckner, 2006).

An ontology for the e-learning processes can be set up in different ways, but every ontology will include a dictionary with explanation of the terms, and indications how the terms are related to another. This approach will give a valid tool for the learning process (Convetini, Alanese, Marengo, Marengo \& Scalera, 2006) and the ontologies represent conceptual descriptions of the specific content as they help to identify appropriate items and relationships in a given knowledge domain. As ontologies show a hierarchical dependence of the terms together with descriptions, explanations, and definitions new users, such as students, as well as software agents are able to understand, use, and incorporate the concepts behind or underlying a knowledge domain.

As Smrz (2004) points out the role of ontologies in e-learning is often underestimated. They can be useful for systems which have to interact (interoperability) and for the development process itself (reusability, reliability and specification process). We use ontologies in a threefold manner: (1) describing the semantics of the e-learning process, (2) structuring activities and communication facilities, and (3) defining the context and the environment of e-learning.

\section{Semantic Web in E-learning}

During the last few years, the work on the Semantic Web brought new ideas in setting up a new form of web content that is meaningful to computers (Berners-Lee, Hendler \& Lassila, 2001). Several technologies have been developed for constructing and developing the Semantic Web. RDF (RDF, 2001) and its extensions such as OWL (OWL, 2003) have been developed to define metadata schemas, domain ontologies and resource descriptions.

Since the Thai learning environment requires the provision of knowledge and learning contents in various forms there is a need for semantic-based annotation of the e-learning material, easy restructuring of the e-learning design, and individualized delivery of the e-learning material (Šimić, Gašević, \& Devedžić, 2004).

In the context of e-learning the conceptual structure of the content is an essential part of the learning material. Losing the contextual information of the content means that the learner will not be able to contextually integrate the concepts that they are trying to learn, which is vitally important in order to achieve an understanding of any specific subject area. Thus, it is important to realize that the meta-data must be understandable for both the human and the machine and will definitely form an important part of the components of the e-learning and communication system.

The Semantic Web, a recent web community effort, is a promising technology for improving semantic interoperability of e-learning components. The main part of the Semantic Web is domain ontologies that should provide a formal description for a shared domain conceptualization. As the new web generation, the Semantic Web has better conditions for composing and reusing elearning materials and contexts. The Semantic Web can be seen as an opportunity to enhance the metadata associated to e-learning materials, expanding the possibilities of current e-learning specifications and standards.

In the ontology-driven e-learning environment we have to model and represent the relevant aspects and domains of knowledge which contains the knowledge about

- students,

- domains,

- learning facilities

- processes, and

- communication 
that are involved. The general concepts that support the above knowledge aspects are implemented as components of e-learning architecture.

Meta-data are data about data (Giarratano \& Riley, 1998). Semantics becomes even more important within the emerging field of e-learning. Extending the Semantic Web provides not only semantic information for the machine, but also conceptual information for the human user.

As a result, the Semantic Web needs a meta-data architecture that is subjective and nonauthoritarian (supporting different views of the same resource), evolving (supporting meta-data of e-learning), and extensible by allowing the introduction of new contexts and components with new semantics. And it must be conceptual, facilitating the evolution of human knowledge.

In the e-learning domain on the other hand there are emerging standards for describing learning resources, among them LOM (Learning Objects Metadata) (Knight et al., 2006). LOM is gradually becoming the reference standard for educational systems managing learning objects of many kinds. However, for our system the standard lacks flexibility as is discussed in the next section.

\section{O-DEST E-learning Requirements, Structure and Design}

In this section we present the requirements, the structure and the design of O-DEST. Specifying reusable structures of e-learning processes and design we need standardized metadata. Standards are chosen according to the scope, the environment, and the requirements of the application. Different organizations have developed their own standardized metadata vocabularies according to their specific needs. Not all of those standards are interoperable. The lack of common understanding between various metadata vocabularies leads to the use of ontologies as a conceptualization for e-learning structure and design. Until now metadata standards have been used to collect the characteristics of the learning object content. However, important information such as usage of the learning objects is often neglected. This kind of information is valuable to show the relevance of the learning object to a particular context, for a particular learner or pedagogical goal (AlKhalifa \& Davis, 2006).

For example, we incorporate a feedback mechanism for the management and content of elearning objects in our system. This feedback is not produced by those who generated the learning objects and can therefore not be part of the learning object metadata.

Therefore, for the creation of the metadata in O-DEST we used parts of the UMES e-learning standards (Buzzetto-More \& Pinhey, 2006), such as instructional activities, interaction, communication and feedback.

Figure 1 shows an outline of the basic components of the system and their general relationships which are described in the following sections.

\section{Details of the Lessons}

In the details of the lessons the structure of each chapter will be rendered more precisely. Details have to cover and meet all objectives of the course. Proper language has to be used, e.g. wording, syntax and presentation of the content have to be considered. Furthermore, the lesson outlines can be set up to the knowledge level of each participant appropriately.

\section{Learning and Teaching Design}

A systematic and appropriate design has to be established. Together with an attractive presentation of the material which leads to a creative learning process there has to be a good interaction with the learners as well. Various user requirements have to be fulfilled individually. Learners have to be able to control the level and process of their lessons. Regular (self) assessments have 


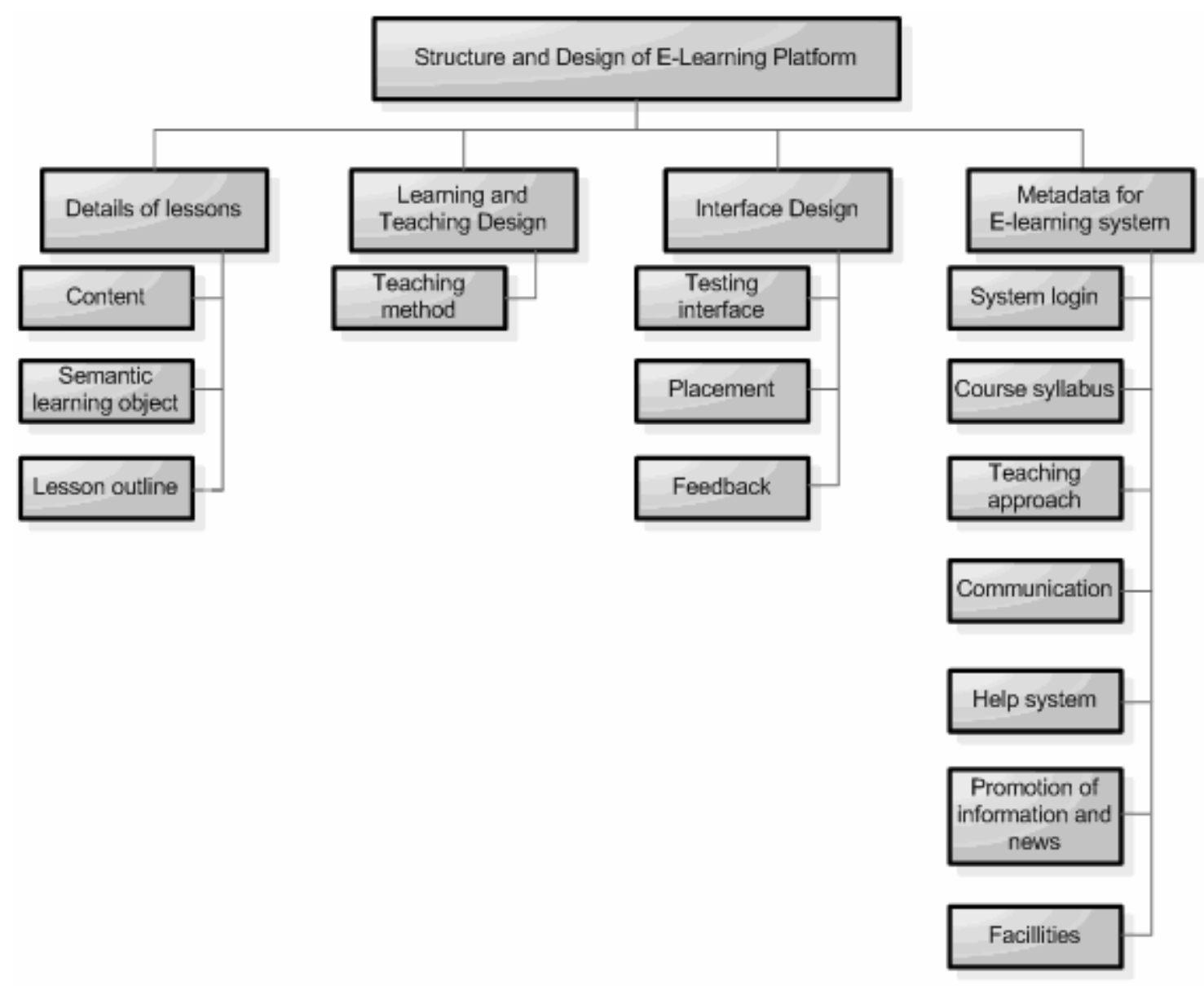

Figure 1. Structure and design of O-DEST

to be designed which help to motivate the learner and lead to more practical work. A further source of motivation is a feedback which the learner can give at every step in the learning process. The system should also help learners to understand and promote thinking and analyzing processes. At every step the learner should be able to use the help system to find best alternatives of the e-learning process.

\section{Interface design}

The user interface must be attractive for Thai students and the content has to be placed in the right place to promote attention. A proper font with the right size, nice colors is important for learners to keep track with the content. Clear and easy to use icons, buttons, graphical representations, pictures and text snippets are presented. The important texts are shown both in English and in Thai. As in every web site the links must be working, no dead links are permitted. For the convenience of the learner all multimedia content has to be presented fast and seamlessly.

\section{Metadata for E-learning System}

Here we show an outline of the metadata used for setting up the e-learning system. The main entry points are the system login, the course syllabus, the teaching approach, learning evaluation, communication between lecturers and learners and learners and learners, help system, promoting information and news, other facilities for teachers and students. Metadata for e-learning management system are defined as a formal description of the management process of e-learning. We use 
an ontology to set up a rich description of every step in the management process as well as the learning objects to serve the Semantic Web. Lytras and Sicilia (2005) show a similar approach used for modeling learning objects to information systems. This approach comprise the selection, composition, integration and assessment of learning objects as well as an assessment of the needs, gaps, and learning activities.

\section{System login}

For the system login we need a user name and a password, both of which have to be identified and have to pass a comparison process. New users have to register before accessing the system for the first time. There are three user levels: lecturer/ or teacher, student or learner and system administrator. The system administrator can be a lecturer but the roles for this system are not the same. Only the administrator can change the user level of a given user.

Here the system stores IP addresses of the login and counts the frequency of accesses and successful and unsuccessful logins to the system. New content can be added by lecturers and by administrators as well.

\section{Course syllabus}

The frame for the course syllabus needs to be filled by the module description, objectives of the course and by assessment constraints (scores vs. grades). Practical work and assignments need to be outlined as well as learning outcomes and learning strategies. Details of the lecturer have to be given, e.g. name, room number, phone number, and contact times for online communication, teaching subjects, research interests, and personal websites. For the content of the lecture it can be important to mention the bibliography and related websites for suggested reading.

\section{Teaching approach}

The teaching approach outlines the teaching forms, e.g. e-learning lectures, case studies and examples, assignments, homework, quizzes and tests.

Here the lecturer has to state the objectives of each chapter or lesson and their main contents. The assignments and exercises must fit to the content already learned and be combined by practical work. Downloadable files have to presented as HTML, XML, presentation material (such as PowerPoint slides, Word files and PDF), multimedia content is important in this context, such as video files (streamed or for download), graphical material and sound to illustrate the learning content.

Assignments are set according the constraints set at the beginning of the course. They are handed out after the student worked through the material and passed a quiz or test. The submission of the assignment or homework results must be done online (by uploading files) or by e-mail. By submission of the results the assignment parameters are checked, e.g. due date and time.

\section{Learning evaluation}

Learning evaluation can be tests, quizzes and so on. They are made before and after lessons in each defined chapter. The formal exams can be done at any time, usually in mid-term and final tests.

\section{Communication}

Communication is an important activity during e-learning process. The classical way to do this is by web boards. Web boards can be set up for learner communities, for teacher communities separated, or for mixed student and lecturer groups which may act as a knowledge exchange hub, 
admin web boards. All web boards are open for discussion. Other forms of communication comprise chat rooms which are very important in Thai learning environment and e-mail as well.

Here we can interact via webcams as appropriate which is similar to face-to-face teaching approach, sometimes called e-mentoring. Also there is a help web board which covers questions about the use of the e-learning system.

\section{Help system}

The system has to provide help to the users, may they be teachers or students. Frequently asked questions can be published in a help file and new questions can be asked via help web board or by E-mail.

\section{Promotion of information and news}

An important part of the e-learning system for Thai students is the advice for studying and proceeding with the learning process. This has to be done in order to assure that the students do not get lost during the e-learning process. Important dates, e.g. exam times and assignments regulations, are given in this area of the website.

Here we also present a table of coming activities (which may include face-to-face activities and formal meetings). Student and research scholarships are shown here as well as student jobs and future career, e.g. tutors.

\section{Facilities}

Facilities of the e-learning system include the submission system for assignments (to the students) and their results (to the teacher). Also the marking, scoring and grading process is facilitated by an e-learning system component. Finally updates of the e-learning system are done with the help of a Content Management System (CMS).

\section{E-learning Design}

The learning design strategy has to take into account the learners' specific behavior and cultural background. In case of Thai students for instance there is a great demand of multimedia content which is supposed to add some fun to the learning material. From our teaching experience Thai students tend to be social learners who study in groups, comprehend through visual stimuli and examples or case studies. An extensive study of the Internet and media usage of Thai students has been performed by Vitartas and Sangkamanee (2000).

The course contents of the ontology-driven e-learning platform are used to design learning material for specific learning objectives, target groups, and a specific contexts and knowledge domains, e.g. to use only some specific elements of a learning object, rather than the whole learning object in a specific learning design, to reuse the same learning design in different contexts with different learning objects; and to adapt the content of the same learning object to a specific student. For this we use ontologies to facilitate the e-learning system with a semantic structure, because an ontology gives an explicit definition of the shared conceptualization of a certain domain.

Learning design is applied to describe the coordination of learning events and activities. An ontology provides the vocabulary (terminology or names) for referring to the terms in a subject area, as well as the logical statements that describe what the terms are, how they are related to each other, how components and contexts can or cannot be classified and relate to each other, as well as rules for combining terms and relations to define extensions to the vocabulary (Hendler, 2001; Uschold, King, Moralee \& Zorgios, 1998). With ontologies we can formalize conceptual models and automatically perform semantic operations. 
In a learning environment we need the shared and consistent vocabulary to catalogue and search for learning designs and objects in a repository. Thus use of ontologies will be a key area of future development in e-learning systems with reusable components. The establishment of shared contexts will be on the other hand a key factor for the creation and acceptance of an e-learning design ontology. Finally, an e-learning platform should enable the reuse of the same learning design within different learning contexts.

\section{System Design}

The system consists of four main parts as follows (see Figure 2):

- Log in module: is to check whether or not username and password which users enter are correct. Users have to register first to get a username and password (will be stored in a database) before getting into the system. If users type in a wrong username and password the system generates an error message and they need to re-enter the correct username and password, else the system allows users to get into the main part of e-learning system.

- Take course module: is to allow users to learn by choosing subjects they want to study. They can download lessons in each subject or can learn online via the internet with the help of a multimedia system.

\section{E-Learning: System Architecture}

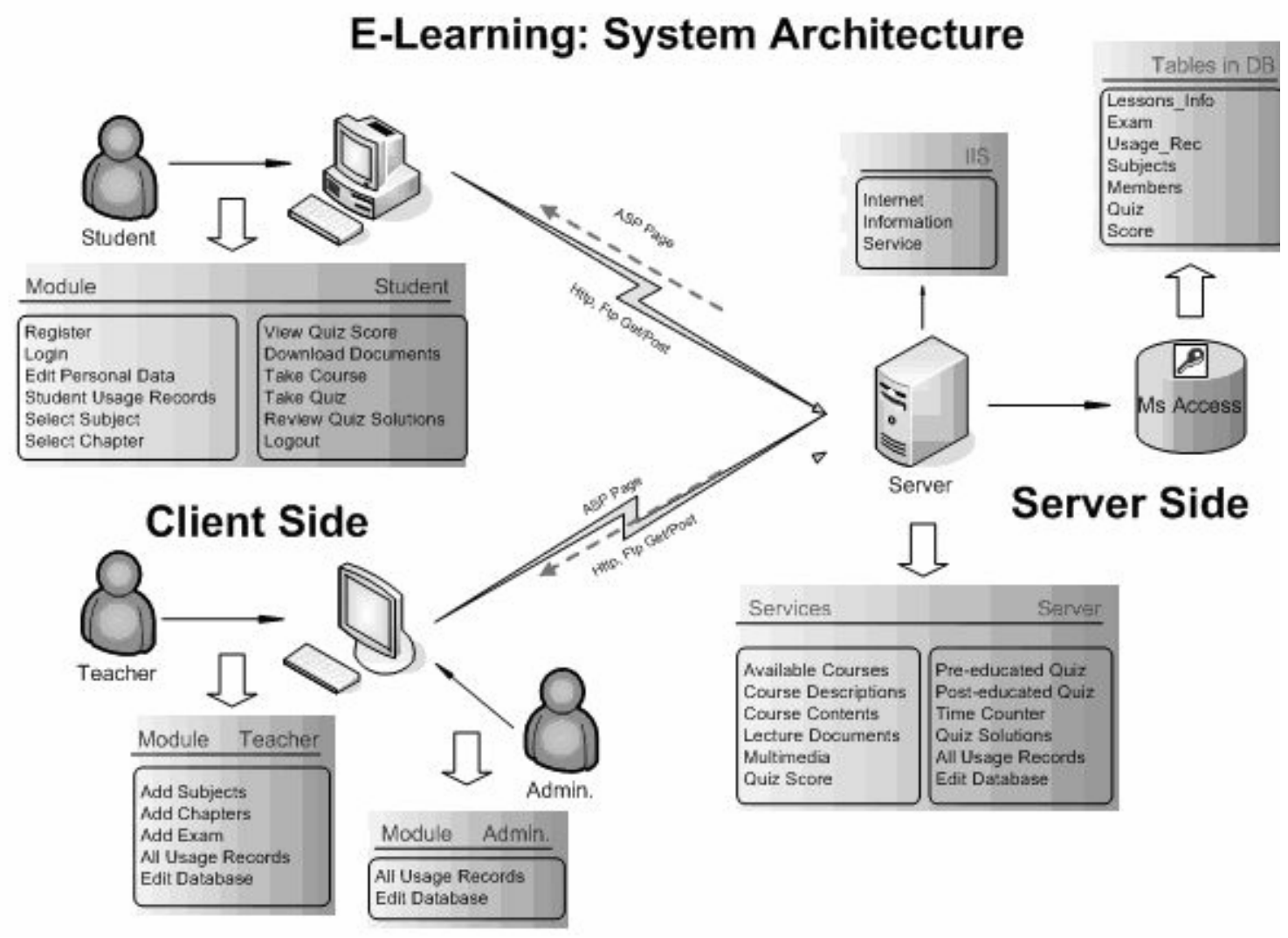

Figure 2. Architecture of the e-learning system 


\section{Ontology-Driven E-Learning System}

- Take quiz module: is a system that allows users to test before lessons or their learning outcome (after lessons) as well as midterm and final exams. This can be done within a given time constraint. After users have finished testing, the system marks the scores and gives grading automatically with solutions of the tests and finally displays the results in a formal format.

- Other services such as "edit personal information", show student usage record or history of users who come to learn and use this website, and display the mark and grading results after quizzes are compulsory in the system.

\section{System Architecture Design}

O-DEST is designed with three basic modules: (1) tools for the teachers, (2) tools for the students, (3) tools for the administration. (1) comprises functions which help the teachers in creating learning objects, connecting the objects to existing ones, re-using objects, and capturing the metadata. As teachers are responsible for entering the students' data and observing the progress of the class there is a need for administrative elements in this module. Teachers can monitor results of the tests, quizzes, assignments, and sessions.

(2) is designed to enable students to master the learning material and meet the learning goals of the course. Students can communicate their expectations and interests, favorites, predispositions and real skills. In the use of system they are guided through the learning material and can actively mark important points, get contextual help and are subject to skills measurement. Students can also collaborate with other students, teachers, and administrators.

(3) supports different management functions and tasks of the system. For example: maintaining and updating student and teacher records, administering the domain knowledge and functions for the system and data security.

O-DEST is best used with highly structured learning modules which are then transparent and accessible via the web. It enables the usage of Semantic Web functions to structure, re-use and compose learning material. Furthermore knowledge presentation in different subjects will be distributed to appropriate agents.

The system architecture of the e-learning system uses client / server as it is designed as a webbased system with data transfer.

The client side has the following modules:

- Register: is for new users/members to fill in the information about themselves so that they get access to the e-learning system

- Login: is for checking and confirming username and password of users/members before granting access to the system

- Edit personal data: is used for updating personal information of users/members

- Student usage record: is for showing the history of access and learning of each user/member

- Select subject: is for choosing subjects/lessons which users want to learn

- Select chapter: is for choosing chapters of subjects/lessons that users want to learn

- View quiz score: is for checking all marks/scores and results of learning given in percent, it shows the status of the learning process 
- Download documents: is for downloading learning material, e.g. PowerPoint, Word, PDF, and multimedia files

- Take course: is for learning the subject that users have chosen

- Take quiz: is for taking quiz/exam after learning the subject

- Review quiz solutions: is for going through explanations and solutions of quiz/exam

- Logout: is for exit from the system

The server side uses ASP for implementing scripts to connect to the database (MySQL is used as the database server as it is easy to install and free; we use seven tables: Lessons_Info, Exam, Usage Records, Subjects, Members, Quiz, Score). The server side comprises the following modules and contents:

- Available courses: is for displaying all subjects for which course material is available for learners,

- Courses descriptions: is for an overview of all subjects and lessons, e.g. how many chapters each subject might have and what the details in each chapter are,

- Courses contents: is for displaying all detail of subjects/courses,

- Lecture documents: is for downloading documentation for each subject or course,

- Multimedia: is for studying by multimedia lessons which can be done using Macromedia Captivate

- Quiz score: is for displaying learning results of oneself

- Pre-teaching quiz: is for testing before taking courses/lessons

- Post-teaching quiz: is for testing after taking courses/lessons

- Time counter: is for displaying time during examination

- Quiz solutions: is for displaying the solution of the tests, examinations, and quizzes

- All usage records: is for displaying history of oneself

- Edit database: is for adding or updating information and data in database

The teacher side contains the following modules and contents:

- Add subjects: is for adding more subjects/lessons

- Add chapters: is for adding more chapters in each subject that is currently available

- Add exam: is for adding, editing and designing quizzes and exams in each subject

The admin side contains the following modules and contents:

- All usage records: is for displaying all or some of the logs of the users/learners

- Edit database: is for adding and updating the database

We use hierarchy of control for the e-learning system to divide the content into three main parts: students/learners, teachers and the administrators (see Figure 3). 


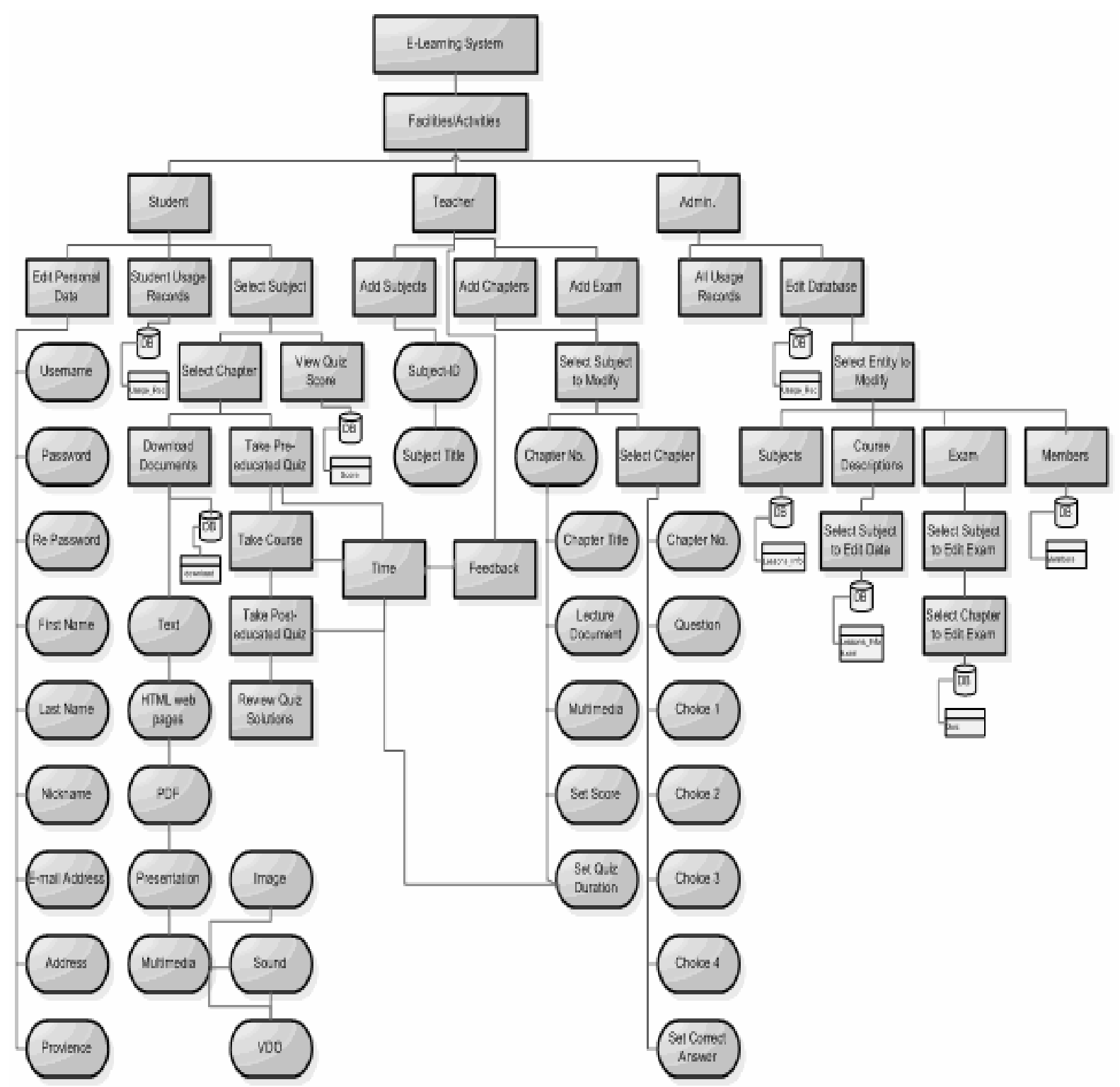

Figure 3. Element of e-learning system

\section{E-learning System and Interface Testing}

Testing reflects the design of hierarchy of control in the e-learning system, thus three main parts of testing are described as follows:

Students: Figure 4 illustrates the main menu for students/learners interface where students can log in to get into the main system. The main page contains learning subjects that available for students, updating system, history of all students, exit from each lesson and log out from the system. 


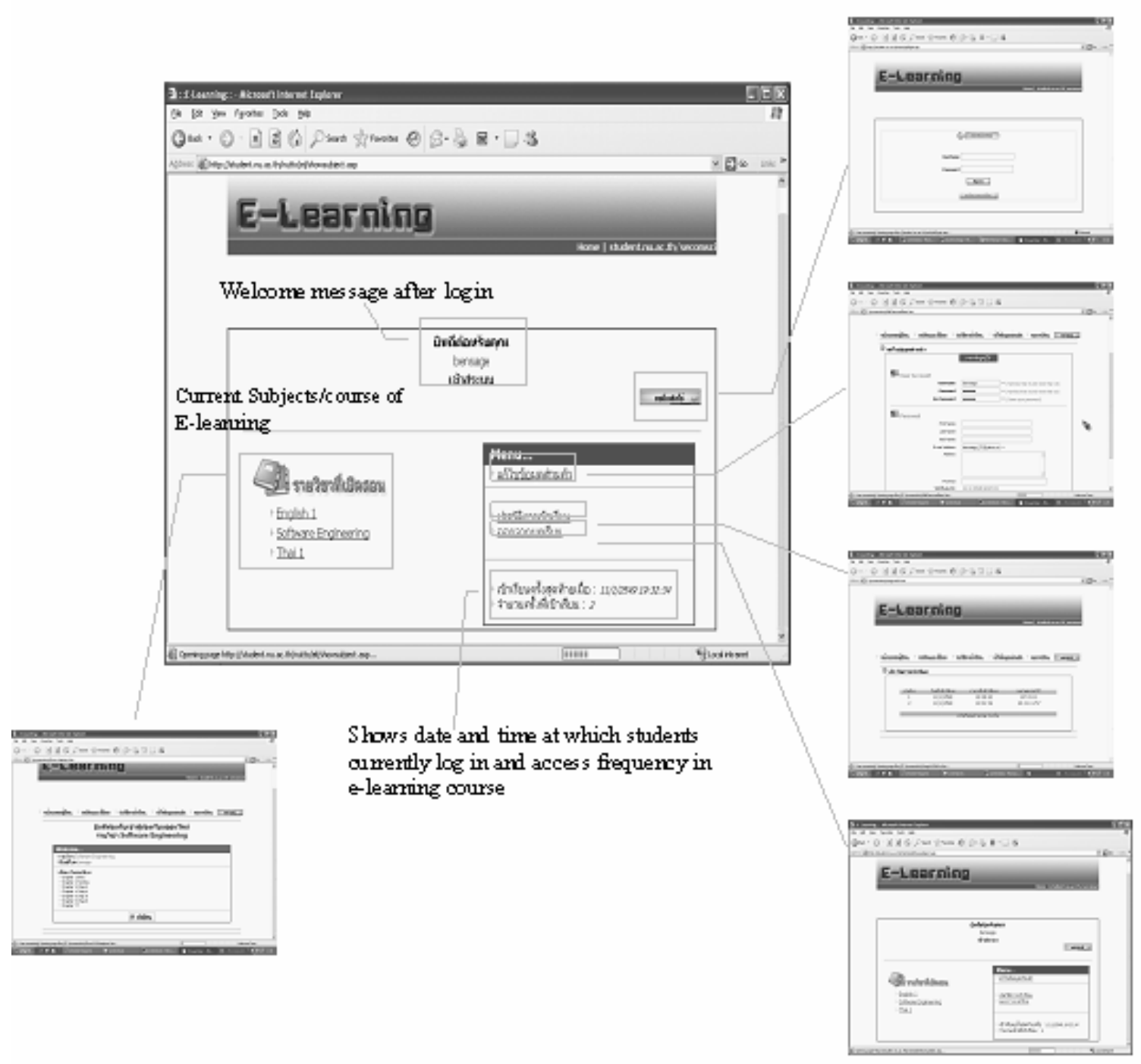

Figure 4. Interface of student main menu

Teachers: Figure 5 shows the main interface for the teachers of the e-learning system (see Figure 3). This admin page contains: Add Subjects, Add Chapters, Add Exam, and Logout from the system. 


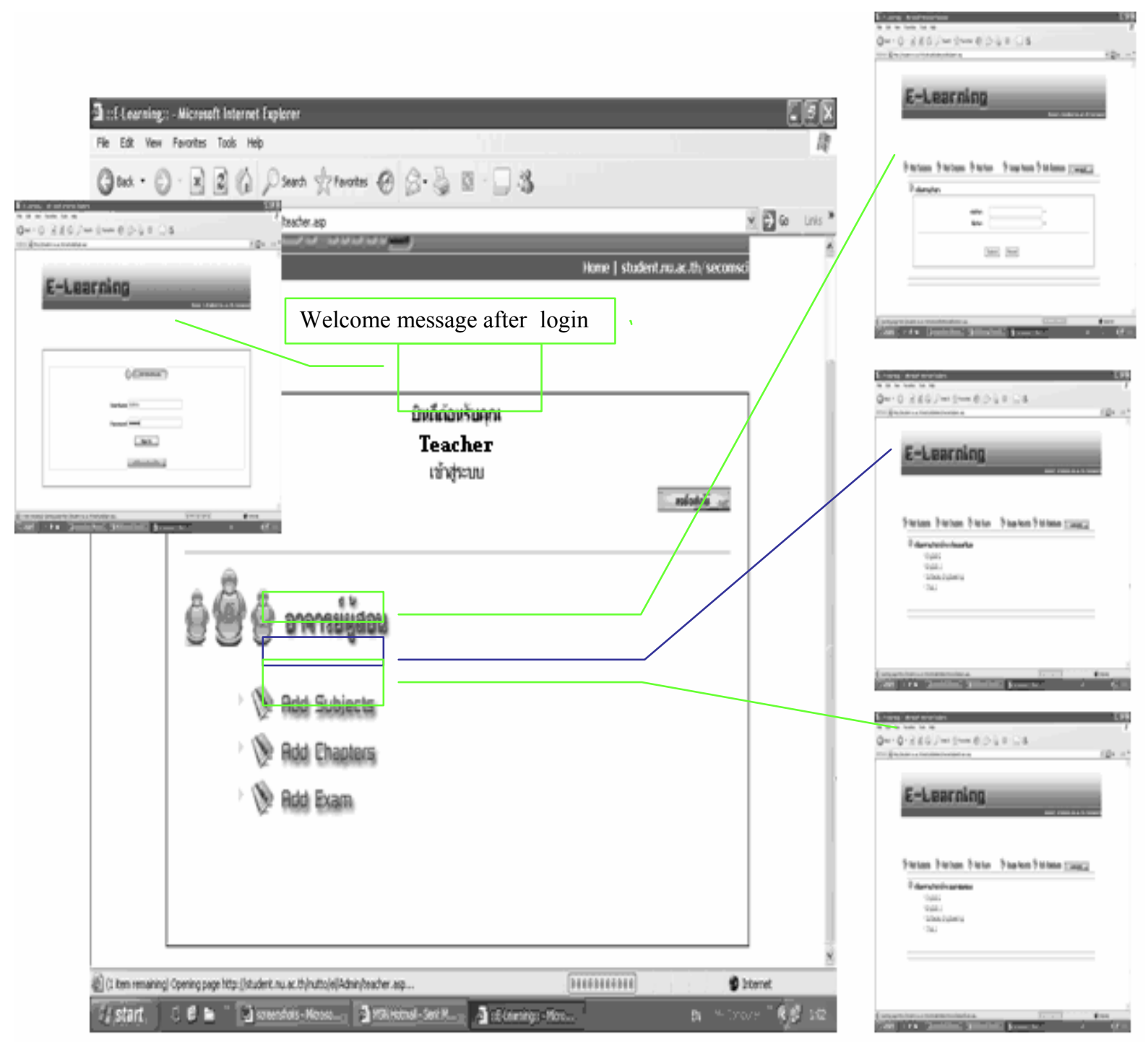

Figure 5. Interface of teacher main menu

Administrators: Figure 6 shows the main interface for the administrator of the e-learning system (see Figure 3). This admin page contains: Usage Records, Edit Database and Logout from the system. 


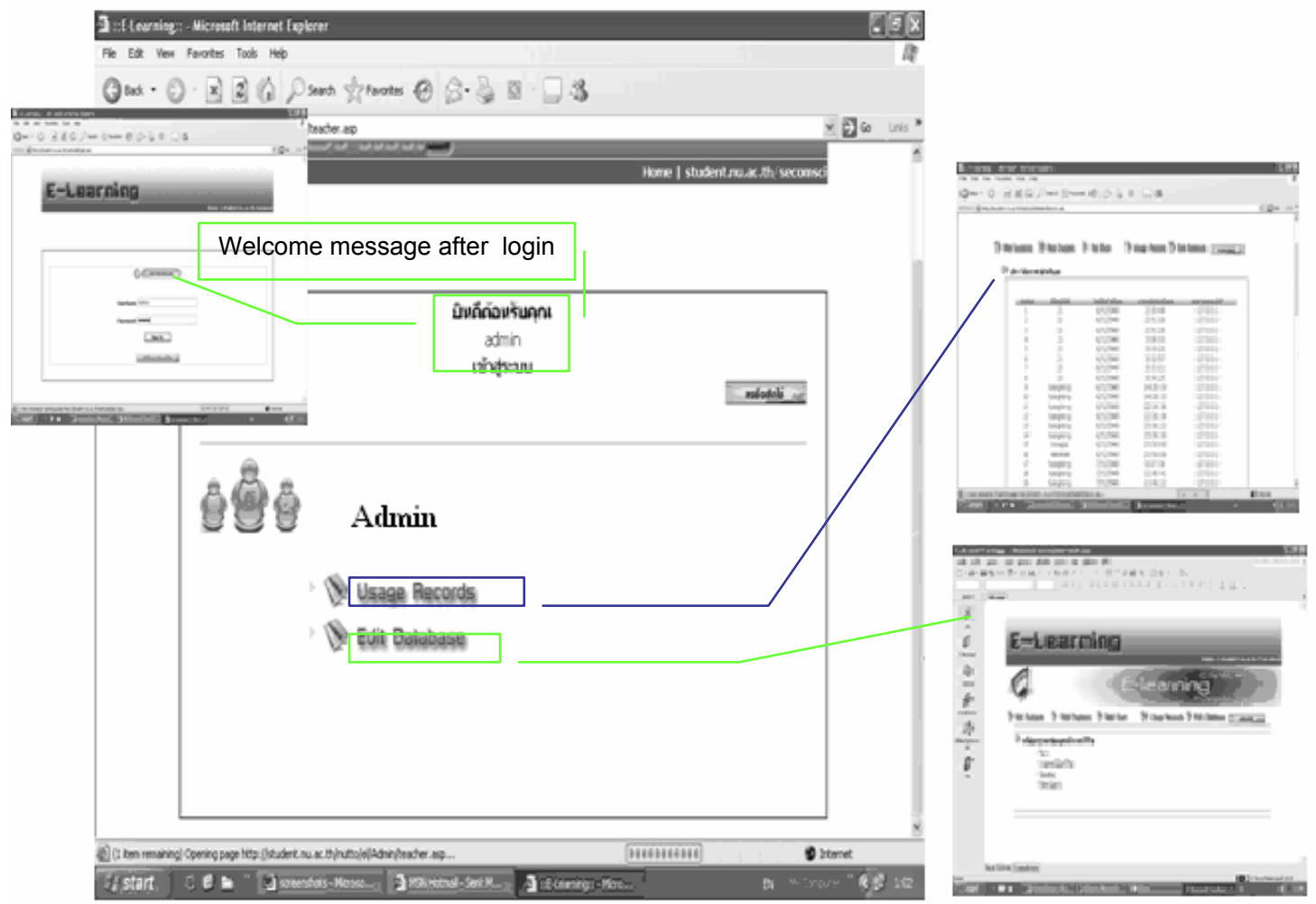

Figure 6. Interface of administrator main menu

\section{Conclusions}

The authors implemented an ontology-based e-learning system for the situation in Thai education which focuses on the specific requirements of the regional students' learning style which is group determined, associative, and visual oriented. The system helps in setting up, learning and evaluating knowledge. As for now the system works as a framework for e-learning systems for Thai students. With the help of appropriate ontologies the system can share and integrate available elearning contents. The ontologies can also help to design the domain model of the contents. We demonstrated the usage of this model in lectures on Software Engineering.

Further work will be done to introduce the automatic allocation of the learning contents according to the student's knowledge and skills which has been gathered from the initial placement test. For this we will implement an ontology-based Assessment of Skills and Knowledge System (ASKS) to construct appropriate questionnaires for the assessment of the students' skills and knowledge in a given subject area. With this we want to find out the individual requirements of the course material which is presented to the student. The results will then be used as an input to an Intelligent Teaching E-Learning Management System (ITEMS) to set up the teaching contents and style suitable for the individual student.

\section{References}

Al-Khalifa, H. S., \& Davis, H. C. (2006). The evolution of metadata from standards to semantics in elearning applications. Proceedings of the Seventeenth Conference on Hypertext and Hypermedia, Odense, Denmark.

Bachman, K. (1999). Corporate e-learning: Exploring a new frontier. W. R. Hambrecht \& Co. Retrieved August 20, 2006, from http://www.actapress.com/PaperInfo.aspx?PaperID=23275 
Bates, T. (2005). Technology, e-learning and distance education. London: Routledge.

Berners-Lee, T., Hendler, J., \& Lassila O. (2001). The Semantic Web. ScientificAmerican. Retrieved September 14, 2006 from

http://www.ryerson.ca/ dgrimsha/courses/cps720 02/resources/Scientific\%20American\%20The $\% 20 \mathrm{~S}$ emantic\%20Web.htm

Brueckner, M., \& Tetiwat, O. (2004). Information literacy for the knowledge-based society Thailand. Naresuan University Science Journal, 1 (1).

Buzzetto-More, N. A., \& Pinhey, K. (2006). Guidelines and standards for the development of fully online learning objects. Interdisciplinary Journal of Knowledge and Learning Objects, 2, 95-104. Available at http://ijklo.org/Volume2/v2p095-104Buzzetto.pdf

Convetini, N., Alanese, D., Marengo, A., Marengo, V., \& Scalera, M. (2006). The OSEL taxonomy for the classification of learning objects. Interdisciplinary Journal of Knowledge and Learning Objects, 2, 125-138. Available at http://ijklo.org/Volume2/v2p125-138Convertini.pdf

Duval, E. (2002). 1484.12.1 IEEE standard for learning object metadata. IEEE Learning Technology Standards Committee. Retrieved October 18, 2006 from http://tsc.ieee.org/wg12/

Giarratano, J. \& Riley, G. (1998). Expert system: Principles and programming (3rd edition). Boston: PWS Publishing Company.

Gruber, T. R. (1993). A translation approach to portable ontology specification. Knowledge Acquisition, 5(2), 199-220.

Guarino, N. (1998). Formal ontology and information systems. In N. Guarino (Ed.), Proceedings FOIS'98 (pp. 3-15), Amsterdam, IOS Press. Retrieved August 25, 2006, from http://www.loa-cnr.it/Papers/FOIS98.pdf

Hendler, J. (2001). Agents and the Semantic Web. IEEE Intelligent Systems, 16(2), 30-37.

Knight, C., Gašević, D., \& Richards, G. (2006). An ontology-based framework for bridging learning design and learning content. Journal of Educational Technology \& Society: Special Issue on Current Research in Learning Design, 9(1), 23-37.

Koper, R. (2001). Modeling units of study from a pedagogical perspective - The pedagogical metamodel behind EML. Retrieved October 18, 2006 from http://eml.ou.nl/introduction/docs/ped-metamodel.pdf

Lytras, M. D., \& Sicilia, M.-A. (2005). Modeling the organizational aspects of learning objects in Semantic Web approaches to information systems. Interdisciplinary Journal of Knowledge and Learning Objects, 1, 255-267. Available at http://ijklo.org/Volume1/v1p255-267Lytras_Sicilia.pdf

Maurer, H., \& Sapper, M. (2001). E-learning has to be seen as part of general knowledge management. Proceedings of ED-MEDIA World Conference on Educational Multimedia, Hypermedia \& Telecommunications, 1249-1253.

Naeve, A., Nilsson, M., \& Palmér, M. (2001). The conceptual web - our research vision. Proceedings of the first Semantic Web Working Symposium, Stanford, July 2001.

OWL. (2003). Web ontology language. Retrieved November 4, 2006 from http://www.w3.org/2001/sw/WebOnt/

RDF. (2001). W3C. Semantic Web activity: Resource description framework. Retrieved November 22, 2006 from http://www.w3.org/RDF/

Šimić, G., Gašević, D., \& Devedžić, V. (2004). Semantic web and intelligent learning management systems. Workshop on Applications of Semantic Web Technologies for e-Learning, Maceió, Brazil. Retrieved November 8, 2006 from http://www.win.tue.nl/SW-EL/2004/ITS-SWEL-Cameraready/SWEL04-ITS-PDF/\%231-Simic-Gasevic-Devedzic-ITS04.pdf 
Smrz, P. (2004). Integrating ontologies into learning management systems - A case of Czech. In R. Meersman, Z. Tari, \& A. Corsaro, OTM Workshops, LNCS 3292, 768-772. Berlin, Springer. Retrieved January 11, 2007 from http://www.springerlink.com/index/PG6PQAGL390PRY3T.pdf

Snae, C., \& Brueckner, M. (2006). Concept and rule based naming system, The Information Universe: Journal of Issues in Informing Science and Information Technology, 3, 619-634. Available at http://informingscience.org/proceedings/InSITE2006/IISITSnae179.pdf

Tetiwat, O., \& Huff, S. L. (2003). Factors influencing the acceptance of web-based online education for Thai educators: impact of Thai culture and values. In: T. Thanasankit, E-commerce and cultural values. Hershey, PA: Idea Group.

Uschold, M., King, M., Moralee, S., \& Zorgios, Y. (1998). The enterprise ontology. The Knowledge Engineering Review, Special Issue on Putting Ontologies to Use, 13(1), 31-89.

Viartas, P., \& Sangkamnee, S. (2000). Profiling Thai student's use of the Internet: Implications for web page design. Proceedings of the ASCILITE Conference. Retrieved November 8, 2006 from http://www.ascilite.org.au/conferences/coffs00/papers/peter_vitartas.pdf

\section{Biographies}

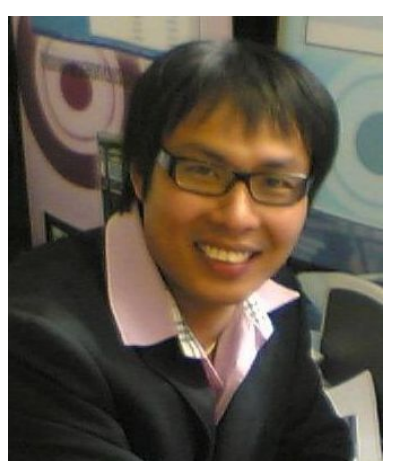

Chakkrit Snae is currently a lecturer at Department of Computer Science and Information Technology, Naresuan University, Thailand. His teaching concept is how to make SE (Software Engineering) evolving to ES (Expert System) by use of AI (Artificial Intelligence) and IS (Information Systems). He is also the head of the research group KIND-HEART (ㅌnowledge-based Intelligent systems using Natural language processing, Data mining, Heterogeneous ontologies and Expert system Application, Research and Technology).

He received a Ph.D. in Computer Science from University of Liverpool, England, M.Sc. in Computer Science from University of Newcastle upon Tyne, England, and B.Sc. in Mathematics from Naresuan University, Thailand. His research interests include Web Based Technologies, System Applications, Semantic Web, Ontologies, Machine Learning, Data/Web Mining, Intelligent and Expert Systems.

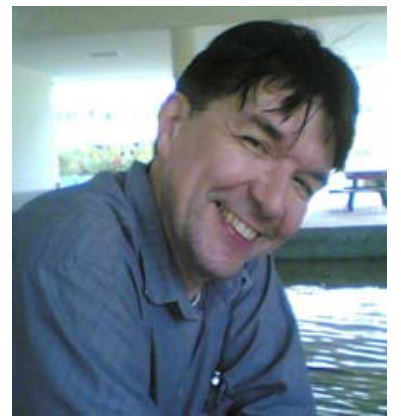

Michael Brueckner is currently lecturer at the Faculty of Science, Naresuan University, Phitsanulok, Thailand, and subhead of the research group KIND-HEART (ㅌnowledge-based Intelligent systems using Natural_language processing, Data mining, Heterogeneous ontologies and Expert system Application, Research and Technology).

He earned a diploma in physics (Dipl. Phys.) from the Technical University Munich, Germany, and worked on simulation software for physical processes, Computer-Aided Design, project management and software quality assurance. He is involved in the field of knowledge and information management since more than two decades. His current research interests are Semantic Web technologies, ontologies, natural language processing and intelligent systems. 